\title{
Microbiota of Fermented Beverages
}

\author{
Maurizio Ciani ${ }^{1, *(1)}$, Ilaria Mannazzu ${ }^{2}$ and Paola Domizio ${ }^{3}$ \\ 1 Department of Life and Environmental Sciences, Polytechnic University of Marche, Food, Industrial and \\ Environmental microbiology Lab. Via Brecce Bianche, 60131 Ancona, Italy \\ 2 Department of Agricultural Sciences, University of Sassari, Viale Italia 39, 07100 Sassari, Italy; \\ i.mannazzu@uniss.it \\ 3 Department of Agricultural, Food and Forestry Systems (GESAAF), University of Florence Via Donizetti 6, \\ 50144 Firenze, Italy; domizio@unifi.it \\ * Correspondence: m.ciani@univpm.it; Tel.: +39-071-220-4987
}

Received: 7 September 2018; Accepted: 12 September 2018; Published: 16 September 2018

\begin{abstract}
This special issue collected recent developments on the microbiota of fermented beverages, from raw materials to the finished product, as well as the use of specific starter cultures. In particular, several studies investigated the occurrence and use of conventional and non-conventional yeasts in distilled alcoholic beverages, wine, and beer production, while other papers investigated probiotic and health-promoting compounds. Results indicated that the management of microbiota greatly improves the analytical, sensorial, and healthy characteristics of fermented beverages.
\end{abstract}

Keywords: fermented beverages; Saccharomyces cerevisiae; non-conventional yeasts; microbiota of raw materials; mixed fermentation

The microbiota of fermented beverages is a complex microbial community made of indigenous microorganisms naturally associated with the raw materials and/or the microorganisms that are present on the equipment and surfaces of processing sites (man-made niches, i.e., wineries), where selected microorganisms may be inoculated as starter cultures.

Since the microbiota is responsible for the transformation of raw materials into the final product, it greatly influences the organoleptic characteristics and sensorial properties of the final product and may impact on the content of probiotics and health-promoting compounds of fermented beverages. Thus, the microbiota of fermented beverages produced in different regional habitats is a topic of increasing interest.

This special issue collected research papers and reviews about recent developments within this research topic. Several studies have investigated specific and peculiar features of non-conventional yeasts in winemaking and their interactions with Saccharomyces cerevisiae, the main actor of fermentation [1-5]. Other reports focus on the microbiota of specific ecological niches, such as sherry wines [6], malting and brewing environments [7], and banana wastes [8]. Selected indigenous S. cerevisiae strains coming from Piceno DOC wines were also investigated by Agarbati et al. [9], while Capece et al. [10] reviewed recent developments on the use of conventional and non-conventional yeast in beer production. Regarding the use of probiotic microorganisms, two papers reported the results of the use of Lactobacillus ramnosus GR1 in fortified fruit juices and white rice pudding [11,12], while Ranadheera et al. [13] reviewed probiotic delivery through fermentation in dairy and non-dairy beverages. Finally, Guerrini et al. [14] investigated the production of health-promoting compounds in S. cerevisiae under winemaking conditions.

In general, all these authors conclude that by deepening the current knowledge on the microbiota of fermented beverages, it will be possible to greatly improve the management of the fermentation processes and of the analytical, sensorial, and healthy characteristics of final products. In this regard, further investigations are needed to optimize the different desired features in fermented beverages. 
Conflicts of Interest: The authors declare no conflict of interest.

\section{References}

1. Barbosa, C.; Lage, P.; Esteves, M.; Chambel, L.; Mendes-Faia, A.; Mendes-Ferreira, A. Molecular and Phenotypic Characterization of Metschnikowia pulcherrima Strains from Douro Wine Region. Fermentation 2018, 4, 8. [CrossRef]

2. Du Plessis, H.; du Toit, M.; Nieuwoudt, H.; van der Rijst, M.; Kidd, M.; Jolly, N. Effect of Saccharomyces, Non-Saccharomyces Yeasts and Malolactic Fermentation Strategies on Fermentation Kinetics and Flavor of Shiraz Wines. Fermentation 2017, 3, 64. [CrossRef]

3. Romani, C.; Lencioni, L.; Gobbi, M.; Mannazzu, I.; Ciani, M.; Domizio, P. Schizosaccharomyces japonicus: A Polysaccharide-Overproducing Yeast to Be Used in Winemaking. Fermentation 2018, 4, 14. [CrossRef]

4. Sgouros, G.; Chalvantzi, I.; Mallouchos, A.; Paraskevopoulos, Y.; Banilas, G.; Nisiotou, A. Biodiversity and Enological Potential of Non-Saccharomyces Yeasts from Nemean Vineyards. Fermentation 2018, 4, 32. [CrossRef]

5. Vilela, A. Biological Demalication and Deacetification of Musts and Wines: Can Wine Yeasts Make the Wine Taste Better? Fermentation 2017, 3, 51. [CrossRef]

6. Cordero-Bueso, G.; Ruiz-Muñoz, M.; González-Moreno, M.; Chirino, S.; Bernal-Grande, M.C.; Cantoral, J.M. The Microbial Diversity of Sherry Wines. Fermentation 2018, 4, 19. [CrossRef]

7. Mastanjević, K.; Krstanović, V.; Mastanjević, K.; Šarkanj, B. Malting and Brewing Industries Encounter Fusarium spp. Related Problems. Fermentation 2018, 4, 3. [CrossRef]

8. De Matos, M.E.; Bianchi Pedroni Medeiros, A.; de Melo Pereira, G.V.; Thomaz Soccol, V.; Soccol, C.R. Production and Characterization of a Distilled Alcoholic Beverage Obtained by Fermentation of Banana Waste (Musa cavendishii) from Selected Yeast. Fermentation 2017, 3, 62. [CrossRef]

9. Agarbati, A.; Canonico, L.; Ciani, M.; Comitini, F. Fitness of Selected Indigenous Saccharomyces cerevisiae Strains for White Piceno DOC Wines Production. Fermentation 2018, 4, 37. [CrossRef]

10. Capece, A.; Romaniello, R.; Siesto, G.; Romano, P. Conventional and Non-Conventional Yeasts in Beer Production. Fermentation 2018, 4, 38. [CrossRef]

11. White, J.; Hekmat, S. Development of Probiotic Fruit Juices Using Lactobacillus rhamnosus GR-1 Fortified with Short Chain and Long Chain Inulin Fiber. Fermentation 2018, 4, 27. [CrossRef]

12. Williams, M.; Hekmat, S. Lactobacillus rhamnosus GR-1 in Fermented Rice Pudding Supplemented with Short Chain Inulin, Long Chain Inulin, and Oat as a Novel Functional Food. Fermentation 2017, 3, 55. [CrossRef]

13. Ranadheera, C.S.; Vidanarachchi, J.K.; Rocha, R.S.; Cruz, A.G.; Ajlouni, S. Probiotic Delivery through Fermentation: Dairy vs. Non-Dairy Beverages. Fermentation 2017, 3, 67. [CrossRef]

14. Guerrini, S.; Mangani, S.; Romboli, Y.; Luti, S.; Pazzagli, L.; Granchi, L. Impact of Saccharomyces cerevisiae Strains on Health-Promoting Compounds in Wine. Fermentation 2018, 4, 26. [CrossRef] 